\title{
Analysis of Void Structure in Deforming Packed Bed of Mono- dispersed Spherical Particles
}

\author{
Hiroshi NOGAMI ${ }^{1 * *}$ and Takuto YAMAWAKI ${ }^{21}$ \\ 1) Institute of Multidisciplinary Research for Advanced Materials, Tohoku University, 2-1-1, Katahira, Aoba-ku, Sendai, 980- \\ 8577 Japan. \\ 2) Graduate School of Engineering, Tohoku University, 2-1-1, Katahira, Aoba-ku, Sendai, 980-8577 Japan.
}

(Received on March 4, 2020; accepted on April 9, 2020)

\begin{abstract}
The void structure in the deforming packed bed like cohesive zone of blast furnace was discussed. The examined packed bed consisted of mono-dispersed spherical particles and was numerically prepared by using the discrete element method. From the obtained packing particle structure, the characteristics of the void space, namely voidage, surface area, hydraulic radius, flow path network structure, width and length of the flow path, were extracted. The actual hydraulic radius deviated from the one calculated from the bed shrinkage with the bed deformation, and this deviation resulted the large difference in the pressure drop in the packed bed. The flow path (void) network was successfully extracted from the particle packing structure. Additionally, distributions of the path width and length were obtained. The choking of flow path with bed shrinkage can be quantitatively visualized. In the softening ore particle bed with nut coke mixing, the flow path structures around ore and nut coke particles showed different behavior. With the obtained characteristics of the void structure, the variations of the pressure drops in the reduction test under loading and in the softening ore layer with coke mixing can be explained.
\end{abstract}

KEY WORDS: void network structure; hydraulic radius; deforming packed bed; cohesive zone; nut coke mixing; blast furnace.

\section{Introduction}

Cohesive zone is one of the most important zones of the blast furnace since the major part of the pressure drop in the furnace is generated in this zone. Excessive pressure drop disturbs the burden descent and causes malfunction of the blast furnace operation. In the cohesive zone, the particles of iron bearing materials (sinter, pellet and lump ore) soften and deform. With the deformation of the particles, the void space among the ore particles are excluded, and gas permeability of the bed decreases. Thus the softening and deforming behaviors and the variation of the permeability and the pressure drop in this deforming bed are important properties of the raw materials of blast furnace. Many approaches using reduction test under loading have been made. ${ }^{1-8)}$ In these trials, the contraction/shrinkage of the bed of iron bearing materials and pressure drop are usually measured, and several indices are obtained to evaluate the permeability. It, however, is difficult to obtain the internal states of the ore bed, thus quantitative analysis on the relationship between the pressure drop and the bed deformation has yet to be discussed. Liu, et al. ${ }^{7)}$ applied the X-ray and Neutron computed tomography, and succeeded to visualize the deformation of the particles and the void space in a lump ore packed bed.

\footnotetext{
* Corresponding author: E-mail: nogami@tohoku.ac.jp DOI: https://doi.org/10.2355/isijinternational.ISIJINT-2020-126
}

Although they clearly showed the variation of the vertical distributions of average fractions of ore, coke and void, the quantitative analysis of the pressure drop using information derived from the CT images is still a task.

Macroscopic gas flow and pressure drop in the cohesive zone were analyzed by the several blast furnace models. ${ }^{9-12)}$ These analyses clearly showed the effect of the cohesive layer on the macroscopic gas flow behavior. In these analyses, the packing properties like voidage and apparent particle diameter in the cohesive layer were preliminary specified or given by the functions of temperature. In recent year, the discrete element method (DEM) ${ }^{13)}$ has been applied to the bed deformation analyses. ${ }^{14-19)}$ In these analysis, the particles were softened with decreasing the Young's modulus, and the deformation of the packed bed was analyzed. The voidage of the packed bed was dynamically obtained from the calculated particle locations, and the packing structure of the bed can be reflected to the estimation of the permeability of the bed. The DEM analysis is combined with the computational fluid dynamic technique and the gas flow behavior and the pressure drop in the cohesive zone were analyzed. ${ }^{15-19)}$ These two-phase flow analyses used the Ergun's equation $^{20)}$ for the estimation of the flow resistance in the packed bed, and simulated the macroscopic gas flow in the blast furnace. The Ergun's equation contains, voidage, particle diameter and particle shape factor as the packed bed properties. Among these voidage can be obtained from the results of the DEM analysis. The treatments of particle 
diameter and shape factor in the deformed packed bed have yet to be established. Sugiyama, et al..$^{21)}$ proposed a method to evaluate the flow resistance of cohesive layer based on the orifice model. In this method, the relationship between shrinkage of ore bed and temperature, the flow resistance of softening ore bed can be estimated. This method, however, contains empirical relation, and is difficult to explain the relationship between the flow resistance and the actual bed structure.

In recent year, several analyses of the fluid flow in the void space in the packed bed have been performed. ${ }^{22-30)}$ The shape of the void space is reflected to the computational grids. Therefore, the effects of the shape and the connection of the void space are automatically reflected to the flow behavior and the pressure drop. Some of these analyses $^{23,28,29)}$ used non-spherical particles. Thus, these approach can be applied to the deforming packed bed like the cohesive zone. Although these analyses can estimate the pressure drop in the packed bed if the packing structure is given, the gas flow behavior and the pressure drop have yet to be discussed from the viewpoint of the void or the flow path structure.

Nut coke mixing to ore layer is considered a technique to improve the blast furnace operation and have been applied to the practical furnace. ${ }^{31-33)}$ One of the merits of this operation is improvement of furnace permeability, and the several reduction tests under loading showed the decrease in the pressure drop. ${ }^{31,34-36)}$ The decrease in the pressure drop, in other words the improvement of permeability was numerically ${ }^{17)}$ and experimentally ${ }^{37)}$ discussed. The former discussed only voidage and stress distribution, and the latter examined the existence of continuous flow paths. Therefore, no clear mechanism to improve the permeability by the nut coke mixing has been given.

Network modeling is one of the major methods to estimate flow and pressure drop in packed bed. Recent approaches have tried to reflect the actual void structure to the formation of the artificial network. ${ }^{38-43)}$ Larachi and coworker ${ }^{38,39)}$ converted computed tomography image to the network with spherical void spaces and connecting throats. The other researchers tried to extract void information from the computed or reproduced packing structures through distribution of sectional void space ${ }^{40)}$ or topological techniques. ${ }^{41-43)}$ With these techniques, important information about the void in the packed bed such as the void network connection, distribution of throat radii, and so on can be revealed, as well as the fluid motion and pressure drop. To apply the network modeling to the cohesive zone of blast furnace, information about the void structure should be further discussed by relating with the bed deformation.

This study focused on the structure of void which is the path of gas in the packed bed, and tried to characterized the void structure that is closely related to the generation of pressure drop in the deforming packed bed. The deformation behaviors of the packed bed that consists of deforming and stiff particles were analyzed using the DEM analysis. Voidage, surface area, hydraulic radius, flow path structure, width and length of the flow paths are extracted from the results of the DEM analysis and discussed.

\section{Method of Analysis}

In this study, the structure of void space in packed bed is discussed. The following sections introduce the procedures of bed formation and the analysis of void structure.

\subsection{Forming Packed Bed}

The packed beds of mono-dispersed spherical particles are numerically formed by using the discrete element method. ${ }^{13)}$ In this method, the motions of all particles that form the packed bed are tracked simultaneously by solving the following equations of motion.

$$
\begin{aligned}
& \text { Translational } \quad m_{\mathrm{p}-i} \frac{d \vec{v}_{\mathrm{p}-i}}{d t}=\sum_{j} \vec{F}_{\mathrm{n}, j \rightarrow i}+m_{\mathrm{p}-i} \vec{g} \\
& \text { Rotational } \quad I_{\mathrm{p}-i} \frac{d \vec{\omega}_{\mathrm{p}-i}}{d t}=\sum_{j} R \vec{F}_{\mathrm{s}, j \rightarrow i}
\end{aligned}
$$

where, $g, m_{\mathrm{p}}, R, t, v_{\mathrm{p}}, I_{\mathrm{p}}$ and $\omega_{\mathrm{p}}$ are gravitational acceleration $\left[\mathrm{m} \mathrm{s}^{-2}\right]$, mass of particle $[\mathrm{kg}]$, particle radius $[\mathrm{m}]$, time $[\mathrm{s}]$, translational velocity $\left[\mathrm{m} \mathrm{s}^{-1}\right]$, moment of inertia $\left[\mathrm{kg} \mathrm{m}^{2}\right]$ and rotational velocity $\left[\mathrm{rad} \mathrm{s}^{-1}\right]$, respectively. The terms $F_{\mathrm{n}}$ and $F_{\mathrm{s}}$ are normal and tangential contact forces that act from the contacting particle(s) and wall(s) [N]. Subscripts $i$ and $j$ mean the particle of interest and the particle(s) contacting to it, respectively.

The contact forces are evaluated based on the Voigt model that includes springs and dashpots. The contact forces in normal and tangential directions to the contact surface are expressed by the following equations.

$$
\begin{gathered}
F_{\mathrm{n}}=B_{\mathrm{n}} \frac{d u}{d t}+K_{\mathrm{n}} u \\
F_{\mathrm{s}}=B_{\mathrm{s}} R \frac{d \varphi}{d t}+K_{\mathrm{s}} R \varphi
\end{gathered}
$$

where, $K$ and $B$ are spring constant $\left[\mathrm{N} \mathrm{m}^{-1}\right]$ and damping constant $\left[\mathrm{kg} \mathrm{s}^{-1}\right], u[\mathrm{~m}]$ and $\varphi[\mathrm{rad}]$ are the translational and rotational displacements $([\mathrm{m}]$ and $[\mathrm{rad}])$. The spring and damping constants are determined from the material properties of the particles. ${ }^{44)}$ When the tangential force is larger than the product of the normal force and the friction constant $\mu_{\mathrm{f}}$, the model allows the slip at the contact point. Under the slip condition, the tangential force is given by the following equation instead of Eq. (4).

$$
F_{\mathrm{s}}=\mu_{\mathrm{f}} F_{\mathrm{n}}
$$

In this analysis, the variation of the void structure with the packed bed deformation is discussed. In the actual blast furnace, the ore particles are softened by the heating and the progress of reduction, and the particles deform due to the powder pressure. The ore particles usually have porous structure. With the particle deformation, the pore volume can be eliminated from the particle. In this case, the apparent particle volume decreases. In this analysis, the particle deformation is expressed by the fairly large overlap between contacting particles. With decrease in the spring constants $B_{\mathrm{n}}$ and $B_{\mathrm{s}}$ in Eqs. (3) and (4), the overlap between the contacting particles increases. These spring constants are given linearly to the Young's modulus of the particle. ${ }^{44)}$ Thus, lower Young's modulus decreases the spring constants, and 
brings larger overlap between particles.

The packed beds for the void structure analysis are prepared by the following simulation procedures.

(a) First, 31250 spherical particles of which diameter and the Young's modulus are $20 \mathrm{~mm}$ and $1.0 \times 10^{8} \mathrm{~Pa}$ are randomly dropped into the rectangular vessel. The horizontal cross section of the vessel is a square of which sides are $0.6 \mathrm{~m}$, and all walls of this vessel has no friction. The friction coefficient $\mu_{\mathrm{f}}$ among particles is set at $0.8[-]$. The simulation of particle motion continues till the formed bed in the vessel becomes stable. At this moment, the packing height is usually about $0.7 \mathrm{~m}$.

(b) Then, the packed bed is divided into two parts. The bed higher than $0.6 \mathrm{~m}$ is weight bed and the bed lower than $0.6 \mathrm{~m}$ is examined bed. Concretely, the weight bed consists of the particles of which centers locate higher than $0.5925 \mathrm{~m}$, and the remaining particles belong examined bed. From the top of the examined bed, the particles of which centers locate in the height range from 0.5875 to $0.5925 \mathrm{~m}$ are extracted and are designated as the marker particles. The average height of the top of the marker particles is defined as the height of the examined bed. Noted that the height of the examined bed at this moment is nearly $0.6 \mathrm{~m}$.

(c) Although all particles initially have the same density of $2580 \mathrm{~kg} \mathrm{~m}^{-3}$, the density of the particles in the weight bed is increased to apply the downward pressure of $0.1 \mathrm{MPa}$ to the examined bed. After applying the increased pressure, the bed formation simulation continues till the stable bed under loaded condition is obtained. The bed height obtained under this condition is treated as the initial abed height.

(d) The particles in the examined bed are further classified into two groups with specified ratio. One is deforming particle and another is non-deforming particle. The former corresponds to the softening ore and the latter corresponds to the nut coke mixed into the ore bed. The Young's modulus of the deformed particles is decreased down to the specified value while the one of the non-deformed particles is kept constant till the end of the packing simulation. The decrease in the Young's modulus is completed in $1.3 \mathrm{~s}$ by selecting the softening particles randomly. The packing simulation continues till the stable condition is established. The packed bed status under this condition will be applied to the analysis of the void structure explained in the following sections. From the preliminary analyses, the bed heights from the different initial packing structures (in procedure (a)) show small fluctuation of which standard deviation is $0.5 \%$ of relative height at maximum, and the effect of the initial packing is considered small enough.

In this study, the ratio of the non-deformed particles to the all examined bed particles is set at $0,5,10,20$ or $30 \%$, and the decreased Young's modulus is $3.16 \times 10^{7}$, $1.00 \times 10^{7}, 3.16 \times 10^{6}$ or $1.00 \times 10^{6} \mathrm{~Pa}$. The analyzing methods of the void structure in the finally obtained beds are explained in the following sections. In the following part of this paper, the deformed and the non-deformed particles are called "ore" and "coke" particles, and the ratio of the non-deformed particles are indicated as "coke mixing ratio".

\subsection{Packed Bed Properties}

The Ergun's equation ${ }^{20)}$

$$
\frac{\Delta P}{L}=150 \frac{(1-\varepsilon)^{2} \mu u}{\varepsilon^{3} \phi^{2} d_{\mathrm{p}}^{2}}+1.75 \frac{(1-\varepsilon) \rho u^{2}}{\varepsilon^{3} \phi d_{\mathrm{p}}}
$$

is widely used for the estimation of the pressure drop in packed bed. In this equation, $d_{\mathrm{p}}$ is particle diameter $[\mathrm{m}], L$ is length of packed bed [m], $P$ is pressure [Pa], $u$ is superficial fluid velocity $\left[\mathrm{m} \mathrm{s}^{-1}\right], \varepsilon$ is voidage $[-], \phi$ is shape factor [-] and $\mu$ is viscosity $[\mathrm{Pa} \cdot \mathrm{s}]$. This equation stands on the hydraulic radius model. Therefore, the hydraulic radius of the deformed bed will be analyzed. The hydraulic radius in packed bed is defined as the ratio of the void volume to the surface area of the packed particle in the bed, and is given by the following equation.

$$
R_{\mathrm{h}}=\frac{\varepsilon}{A_{\mathrm{p}}}
$$

where $A_{\mathrm{p}}$ is specific surface area of packed particles $\left[\mathrm{m}^{-1}\right]$. As mentioned above, this analysis allows fairly large overlap between contacting particles to express the particle deformation. Some parts of particle volume and particle surface are eliminated by the overlap. This study assumes mono-dispersed spherical particles, thus the eliminated part is a spherical cap as shown in Fig. 1. The volume and the surface area of the eliminated spherical cap can be given by the following geometrical relations by using particle radius $R$ and the gap between particles $G$.

$$
\begin{gathered}
\text { Surface area } A_{\text {cap }}=-\pi R G \quad(G<0) \ldots \ldots \ldots \ldots(8) \\
\text { Volume } \quad V_{\text {cap }}=\frac{1}{12} \pi G^{2}\left(3 R+\frac{G}{2}\right) \ldots \ldots \ldots \ldots . . . .(9)
\end{gathered}
$$

The surface area of the particles in the deformed packed bed is given by subtracting all eliminated surface area of the spherical caps from the surface area of spheres. The volume of the particles in the deformed bed is calculated by the same manner. Then the voidage of the deformed bed is given by using this particle volume. Finally, the hydraulic radius of the bed can be obtained.

The hydraulic radius of packed bed of mono-dispersed spherical particles $(\phi=1.0[-])$ is given by

$$
R_{\mathrm{h}}=\frac{\varepsilon d_{p}}{6(1-\varepsilon)}
$$

Thus, the Ergun's equation can be transformed as

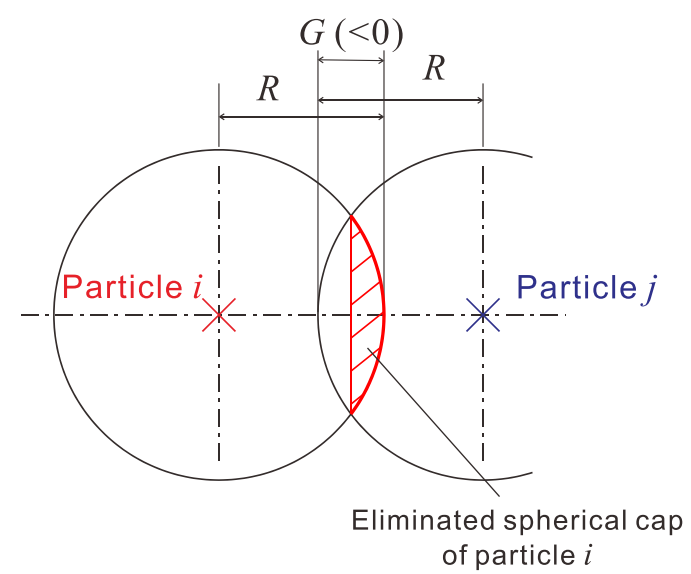

Fig. 1. Eliminated spherical cap due to overlap. (Online version in color.) 


$$
\frac{\Delta P}{L}=\frac{25}{6} \frac{\mu u}{R_{\mathrm{h}}^{2} \varepsilon}+\frac{7}{24} \frac{\rho u^{2}}{R_{\mathrm{h}} \varepsilon^{2}}
$$

The pressure drop of the deformed packed in the deformed packed bed based on the hydraulic radius model is given by this equation.

\subsection{Flow Paths in Packed Bed}

In the packed bed, the gas flows non-uniformly. Several gas flow simulations in packed beds ${ }^{23,24,27,29,30)}$ showed that the gas flow concentrated to fairly thicker flow channels rather than passing through thinner void space. Therefore, it is important to extract the flow channel structure formed in the packed bed. Figure 2 shows the schematic drawing of the thick flow channel formation. In the figure, a thick flow channel surrounded by four spherical particles A, B, $\mathrm{C}$ and $\mathrm{D}$. At the same time, thin void spaces are formed between particles $\mathrm{A}$ and $\mathrm{B}, \mathrm{A}$ and $\mathrm{C}, \mathrm{B}$ and $\mathrm{D}$, and $\mathrm{C}$ and D. When the gas passes this particle structure (perpendicular to the page), it flows mainly through the thick flow channel, not through thin spaces. Thus, it is important to understand the channel thickness and connections quantitatively for evaluating the pressure drop in the packed bed. Although the thick channel shown in the figure is surrounded by four particles, it can be treated that this rectangular flow channel consists of two flow channels surrounded by particles A, B and C, and particles B, C and D. Although the thick channel surrounded by five or more particles can be formed in the packed bed, the possibility is considered low, and threeparticle arrangement can be easily formed. Therefore, the flow channel locating among three particles are extracted in this study.

Figure 3 shows the concept of extracting the flow path surrounded by three particles. In the figure, there are three particles neighboring one another (particles A, B and C). The plane 1 locates between the particles A and B. This plane is perpendicular to the line connecting the centers of particle $\mathrm{A}$ and $\mathrm{B}$, and their intersection point locates on the midpoint of this connecting line. Similarly, the plane 2 locates between the particles $\mathrm{A}$ and $\mathrm{C}$. The flow channel among the particles $\mathrm{A}, \mathrm{B}$ and $\mathrm{C}$ can be given by the intersection line of planes 1 and 2 . These planes and the intersection can be given by the simple geometric relations from the coordinates of three particle centers. Repeating this procedure regarding all the particles neighboring to the

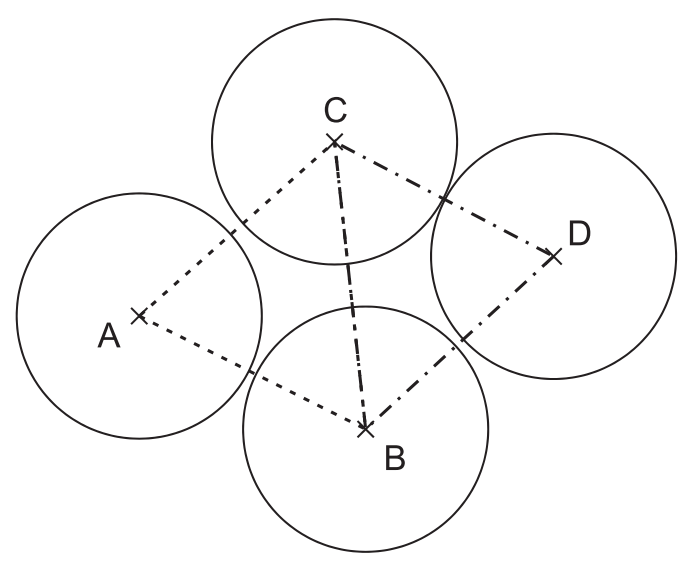

Fig. 2. Flow channel formed among particles. particle A results in the cage-like channel structure around the particle A. After getting all paths in the packed bed, the length and average distance from the centers of surrounding three particles are obtained regarding each path. Figure 4 shows the example of the extracted flow path. In Fig. 4(a) a red particle is surrounded by 16 particles. Following above procedure, a cage-like flow path structure around the red particle is extracted like shown in Fig. 4(b). The size of the surrounding particles is halved for better visibility in Fig. 4(b) while the particle arrangement is same as Fig. 4(a). Similar flow path structures are extracted for all particles, and finally the flow path structure in the packed bed is obtained. Figure 5 shows the example of the flow paths structures in ordered packing structures. In the cubic packing structure, the flow paths have also cubic structure. Thus each particle is surrounded by 12 flow paths having the length equals to particle diameter. The distance from the particle center to the narrowest part of the path is $\sqrt{2}$ times as particle radius. In the hexagonal closest packing structure, a particle is horizontally surrounded by 6 particles. Thus 6 vertical paths that are colored red and blue are formed around each particle. Above and the beneath the particle, 9 paths (colored green) having uniform length are formed. Thus 24 paths surround a particle. The vertical paths indicate two different lengths. The longer (red) paths are vertically connected one another and form straight flow paths. The shorter (blue) paths appears in zigzags with confluence

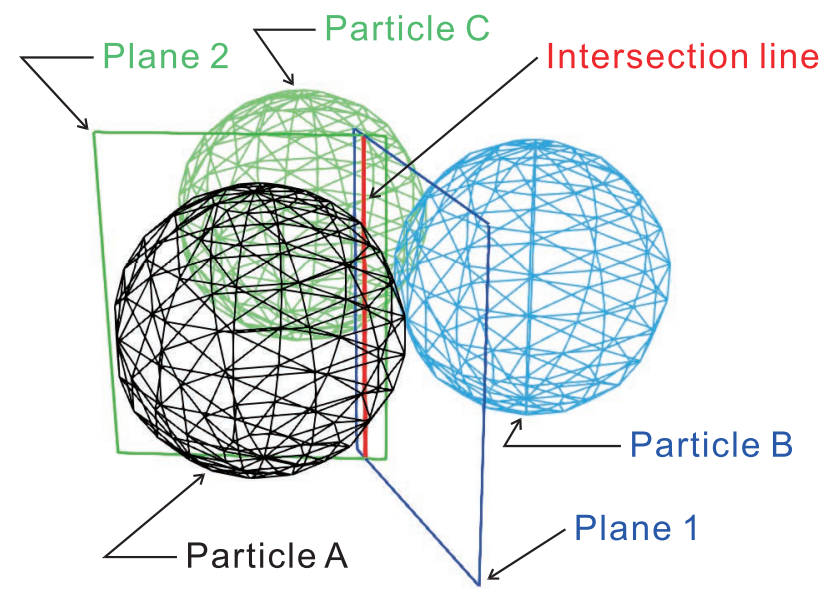

(a) Bird's eye view

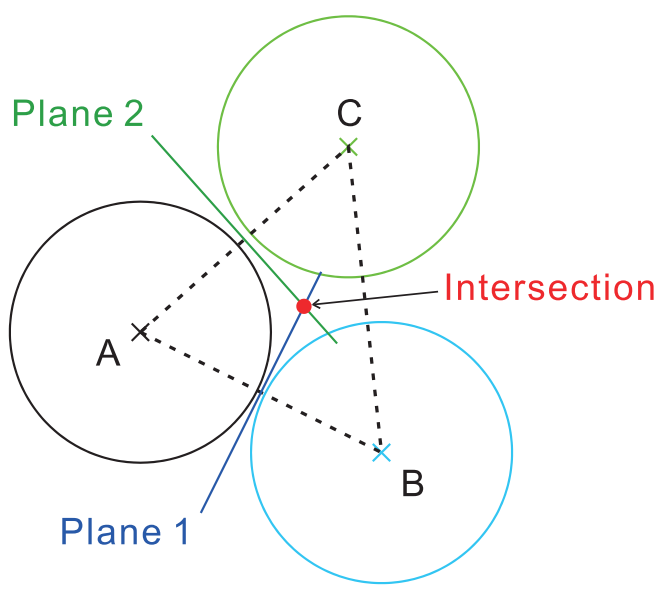

(b) Top view

Fig. 3. Concept to extract flow path among particles. 


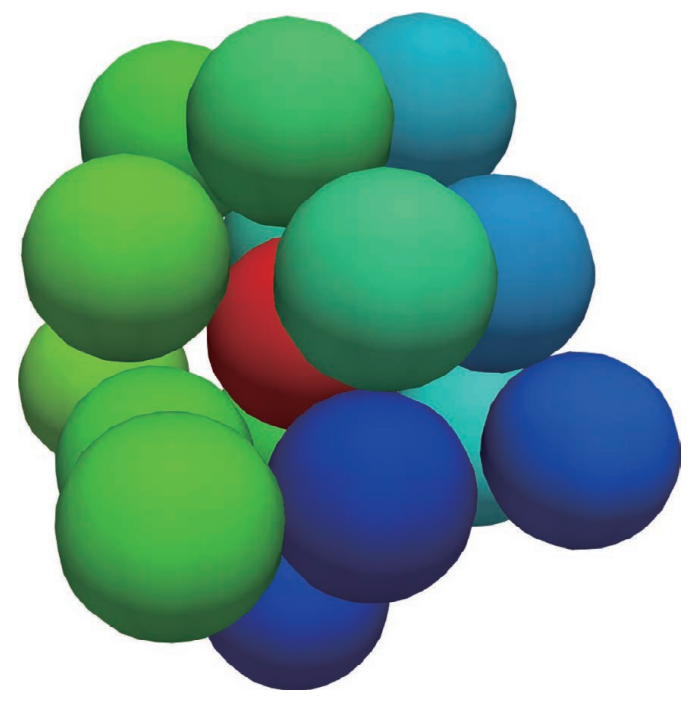

(a) Particle system

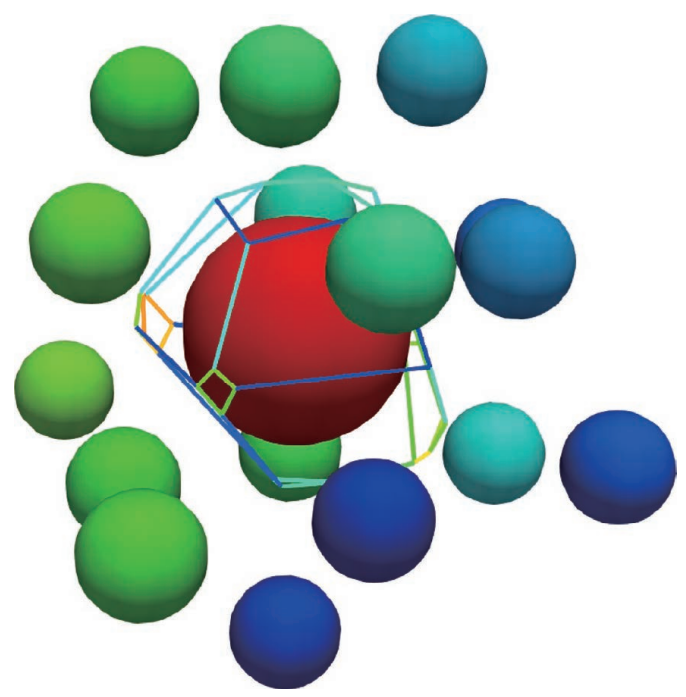

(b) Flow paths around central particle

Fig. 4. Extracted flow paths among particles.

and divergence. The ratios of the vertical longer paths (red), vertical shorter paths (blue) and the other paths (green) are 1:1:6. Although the flow path structure in the hexagonal closest packing consist of paths having three lengths, the distance from the particle center to the narrowest part of the paths are uniform and $2 / \sqrt{3}$ times as particle radius.

\section{Results and Discussion}

\subsection{Bed Shrinkage}

Figure 6 shows the variations of bed height and its shrinkage. The shrinkage is defined as the ratio of reduced height to the initial bed height. The bed height decreases with decrease in the particle Young's modulus regardless of coke mixing ratio. The bed height under $1.0 \times 10^{8} \mathrm{~Pa}$ condition is about $0.588 \mathrm{~m}$, and it decreases to $0.319 \mathrm{~m}$ under $1.0 \times 10^{6} \mathrm{~Pa}$ and no coke mixing condition. The bed height under the same Young's modulus condition increases with the increase in the coke mixing ratio, and the height under $1.0 \times 10^{6} \mathrm{~Pa}$ and $30 \%$ of coke mixing ratio conditions is $0.372 \mathrm{~m}$. The shrinkage under the same Young's modulus condition decreases with the coke mixing ratio.

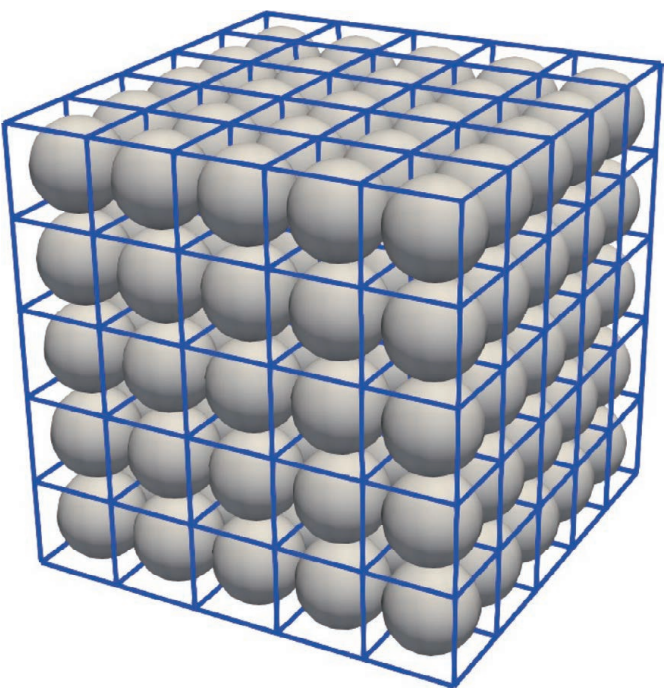

(a) Simple cubic lattice

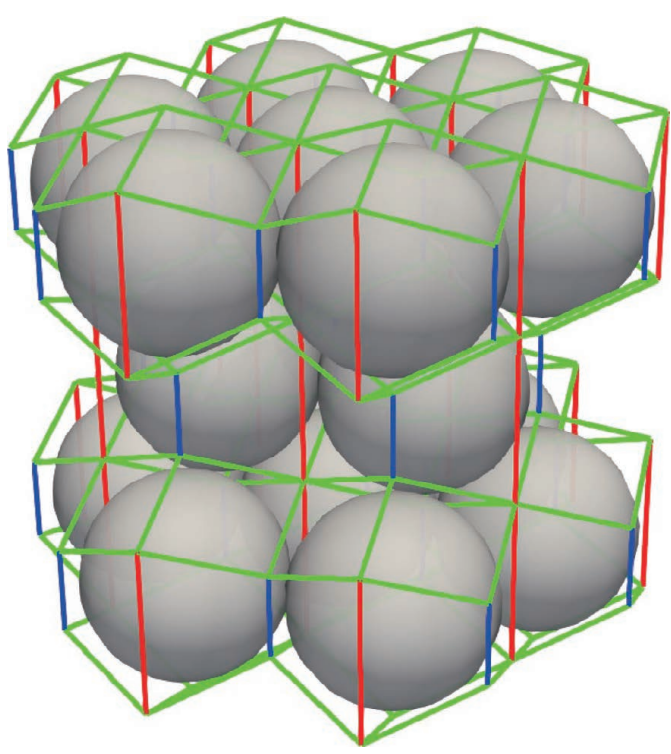

(b) Hexagonal closest packing

Fig. 5. Examples of flow paths in ordered packing structures.

Under $1.0 \times 10^{6} \mathrm{~Pa}$ conditions, the shrinkages in no coke and $30 \%$ coke conditions are 45.8 and $36.8 \%$, respectively. The decrease in the shrinkage under this condition is $19.7 \%$. The average decreases in the shrinkage under coke mixing of 5, 10, 20 and $30 \%$ are 2.6, 5.0, 11.8 and $19.3 \%$. Thus the decrease in the shrinkage with the coke mixing is smaller than the coke mixing ratio.

Figure 7 shows the variation of the voidage of the packed bed with the particle Young's modulus under no coke mixing condition. The voidage that is calculated following the procedure in the section 2.2 , namely exclusion of the overlap spherical caps, is designated as "deformed" and is plotted with circle mark in this figure. At the same time, the voidage which is calculated with conserved particle volume is plotted with cross mark and is designated as "nondeformed". The latter voidage can be expressed as

$$
\varepsilon_{\text {nd }}=\frac{\varepsilon_{0}-S}{1-S}
$$

where, $\varepsilon_{0}$ and $S$ are voidage before bed deformation [-], namely the voidage under $1.0 \times 10^{8} \mathrm{~Pa}$ condition, and the 


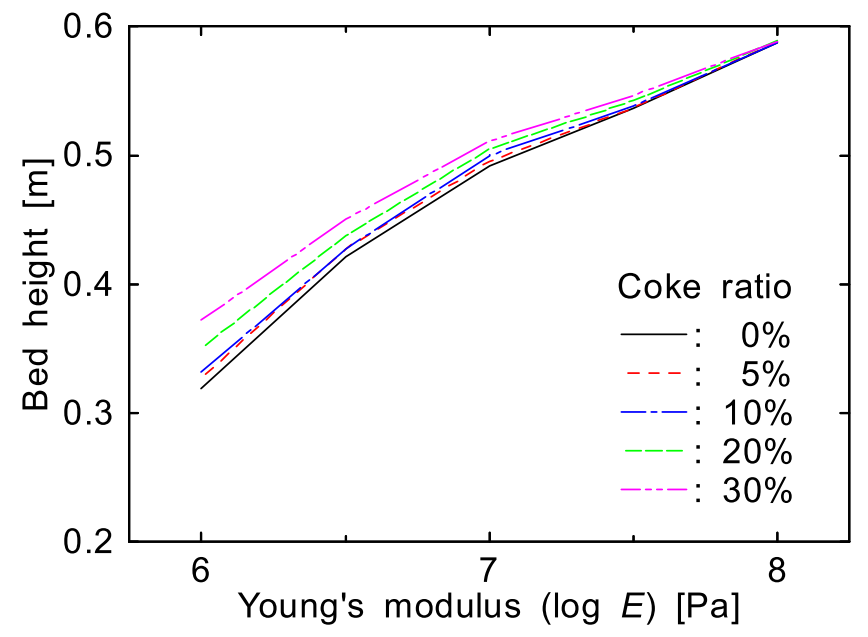

(a) Bed height

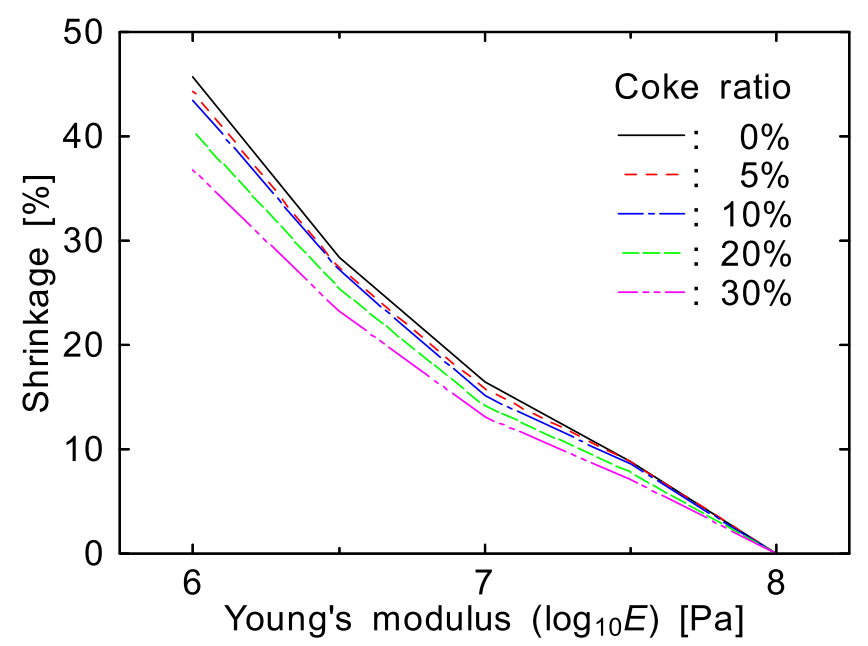

(b) Bed shrinkage degree

Fig. 6. Variation of bed height and bed shrinkage with particle Young's modulus. (Online version in color.)

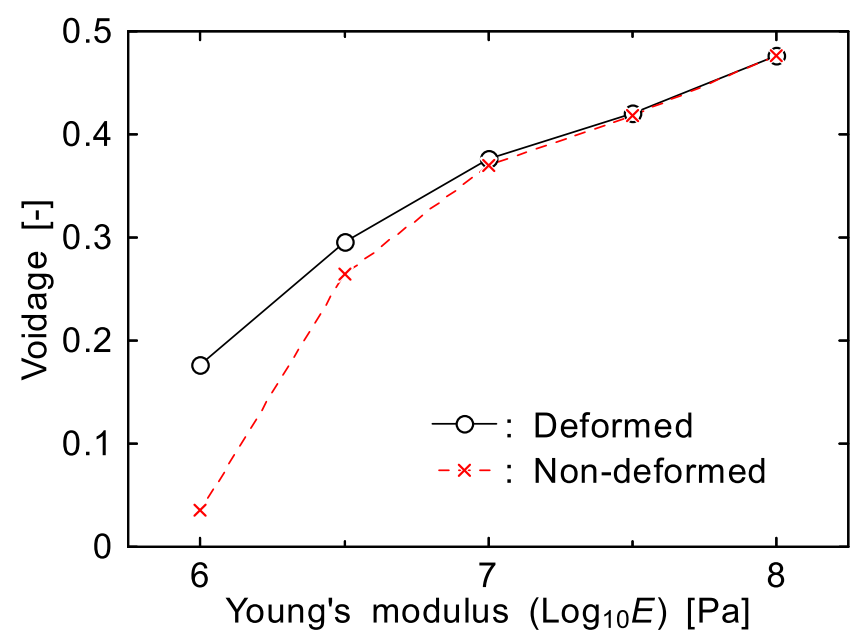

Fig. 7. Variation of voidage with Young's modulus. (Online version in color.)

shrinkage ratio [-], respectively. The voidage decreases with the decrease in the Young's modulus. The decrease in the voidage is smaller than one under conserved particle volume (non-deformed) condition.

The variation of the voidage is replotted against the bed shrinkage and shown in Fig. 8. The voidage under the

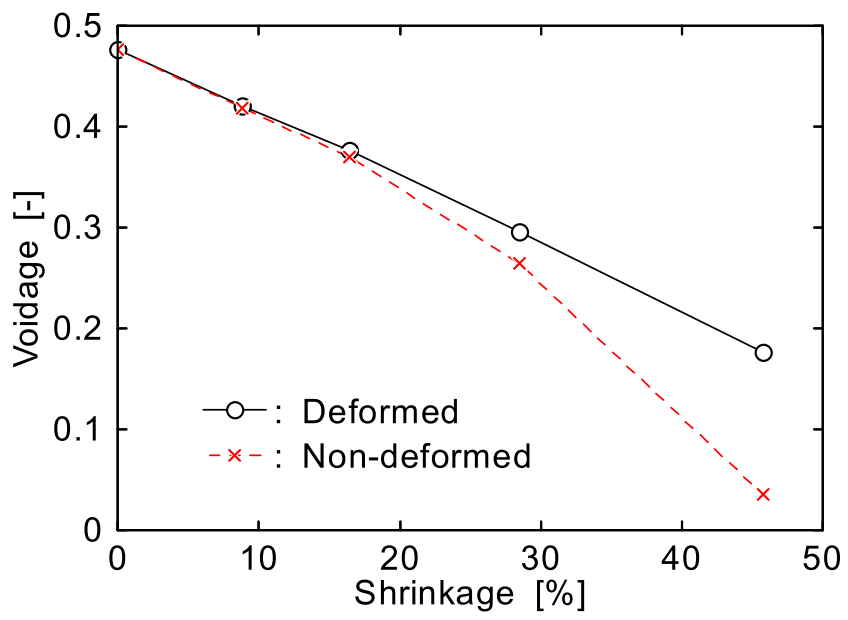

Fig. 8. Variation of voidage with bed shrinkage. (Online version in color.)

particle deforming condition decreases linearly to the bed shrinkage while the decrease in the voidage accelerates with the increase in the shrinkage. The difference between these two cases is small till $15 \%$ of shrinkage, and then increases in the higher shrinkage.

\subsection{Hydraulic Radius and Pressure Drop}

Figure 9 show shows the variation of the hydraulic radius with the Young's modulus. In this figure, the case with elimination of the overlap volume and surface area is designated as "deformed" and the case under which both volume and surface area are conserved is designated as "non-deformed". The hydraulic radius of latter case is given by substituting Eq. (12) to Eq. (10). In both cases. the hydraulic radius before bed deformation is $3.06 \mathrm{~mm}$, and decreases with the decrease in the Young's modulus. Under $1.0 \times 10^{6} \mathrm{~Pa}$ of Young's modulus, the hydraulic radius of deformed case decreases down to $1.45 \mathrm{~mm}$ while one of non-deformed case is $0.12 \mathrm{~mm}$. Similar to the voidage, the variation of the hydraulic radius against the Young's modulus is smaller in the deformed case.

The hydraulic radius is replotted against the bed shrinkage and shown in Fig. 10. The hydraulic radius of the non-deformed case decreases linearly to the bed shrinkage. This relation can be derived by substituting Eq. (12) to Eq. (10). Contrarily, the decreasing rate of hydraulic radius to the shrinkage decreases with the increase in the shrinkage. Therefore, the difference in the hydraulic radius between deformed and non-deformed cases increases with the increase in the shrinkage.

The ratio of the hydraulic radius of the deformed case to the non-deformed case is shown in Fig. 11. Till 30\% of shrinkage, the hydraulic radius ratio increases gradually to $1.55[-]$, while it increases drastically in the higher shrinkage. It reaches $11.9[-]$ at the shrinkage of $45.8 \%$.

The pressure drops in the packed bed are calculated using Eq. (11) with the obtained hydraulic radius, and are shown in Fig. 12. In this figure, the pressure drops of the deformed and the non-deformed cases under the coke mixing ratios of 0 and $30 \%$ are displayed. It is assumed that the air at room temperature (density $1.2 \mathrm{~kg} \mathrm{~m}^{-3}$, viscosity $1.8 \times 10^{-5} \mathrm{~Pa} \cdot \mathrm{s}$ ) flows with superficial velocity of $1.0 \mathrm{~m} \mathrm{~s}^{-1}$. The pressure drop of the packed bed before deformation is 


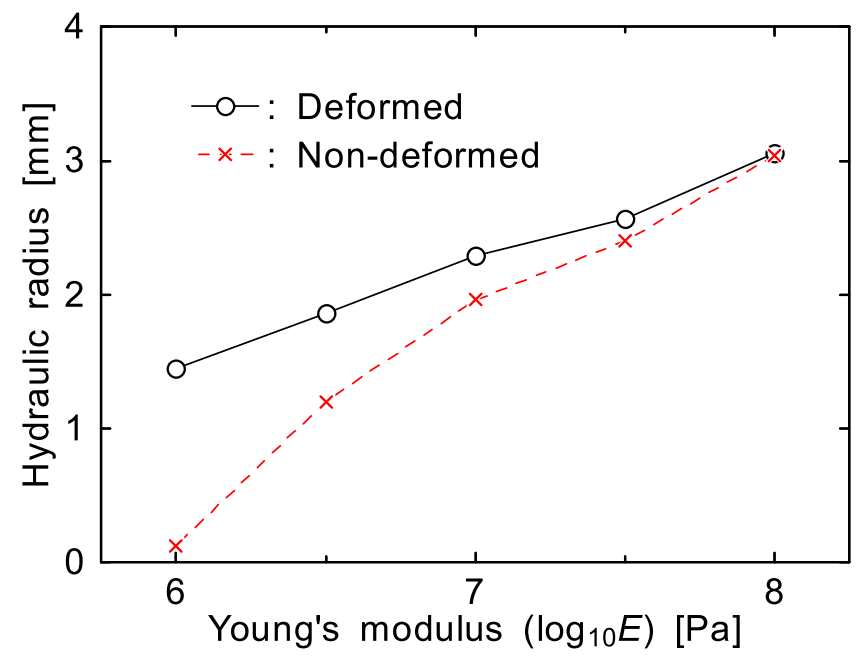

Fig. 9. Variation of hydraulic radius with Young's modulus. (Online version in color.)

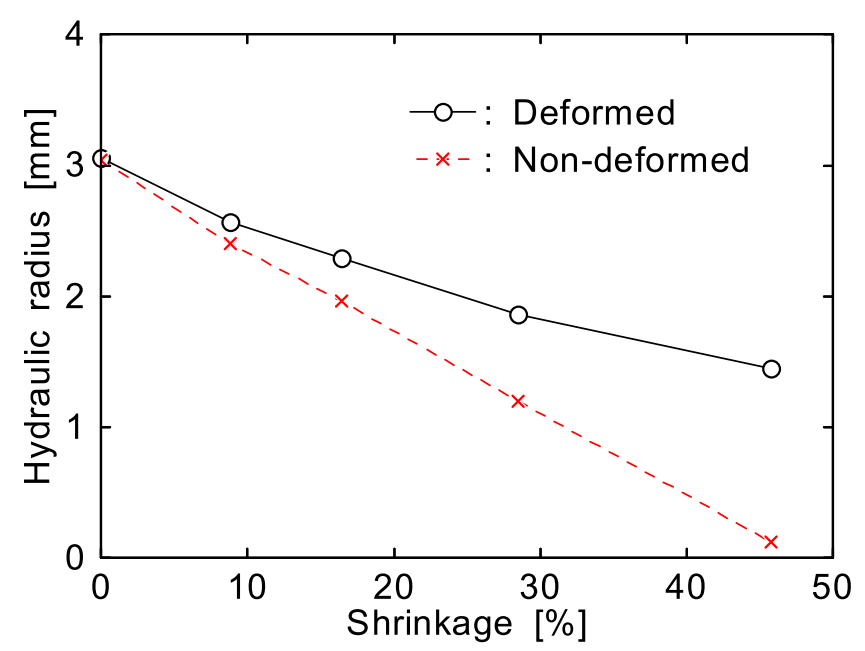

Fig. 10. Variation of hydraulic radius with shrinkage. (Online version in color.)

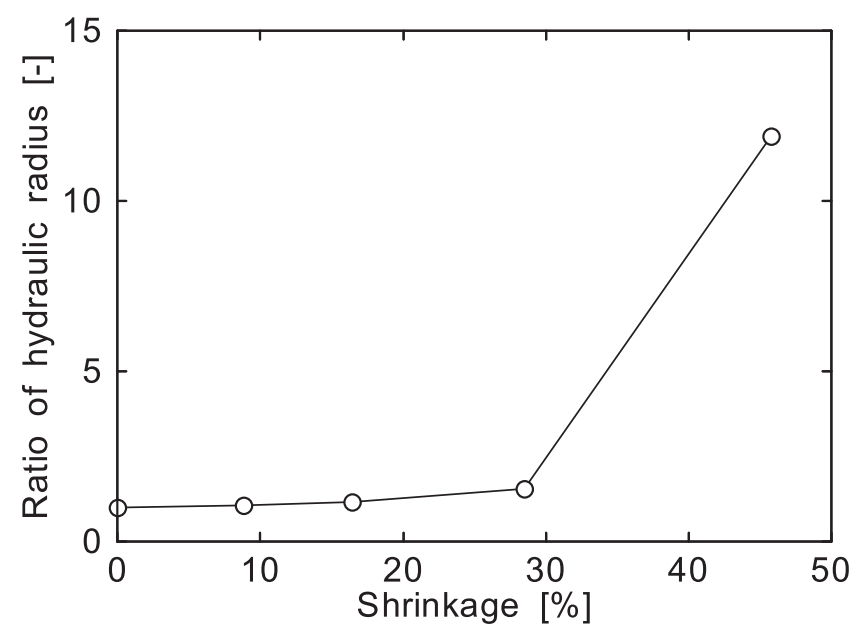

Fig. 11. Variation of Hydraulic radius ratio with shrinkage.

about $520 \mathrm{~Pa} \mathrm{~m}^{-1}$. It gradually increases with increase in the shrinkage up to $25 \%$ in all cases. The pressure drops in the deformed cases continue to increase gradually. Contrarily, the pressure drops in the non-deformed case drastically increase above this shrinkage.

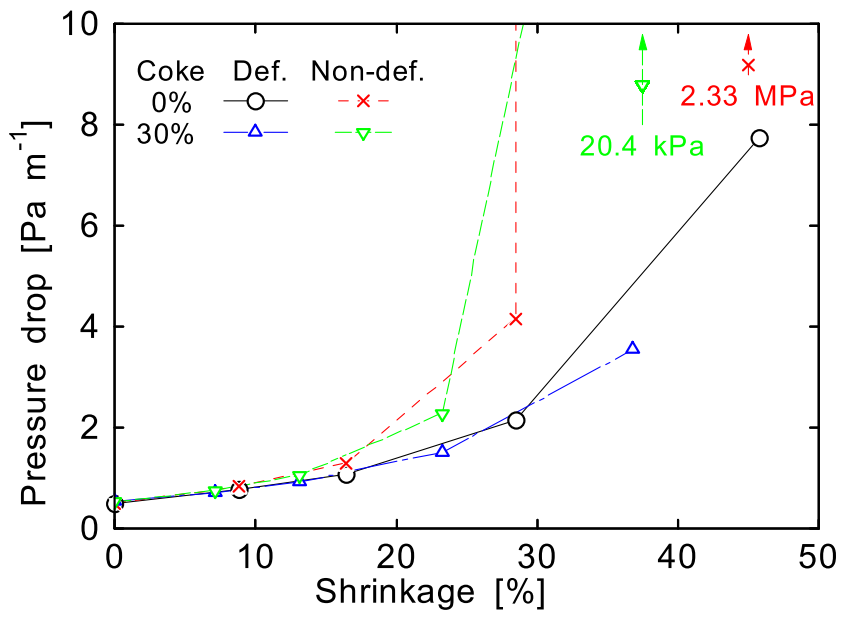

Fig. 12. Variation of pressure drop with shrinkage. (Online version in color.)

It is often observed in loading reduction tests of iron bearing materials that the pressure drop shows little increase in the beginning of the bed shrinkage, and its significant increase appears after some extent of the bed shrinkage. ${ }^{1,4,6,7,31)}$ In this analysis, the overlap of the particle is allowed. With this treatment, the conservation of particle volume is ineffective, and the particle volume decreases with the bed shrinkage. The iron bearing materials, like sinter and pellet, are usually porous materials. Thus the elimination of pore volume from the particle of the iron bearing materials can occur with the particle deformation. In this case, the apparent particle volume decreases. Therefore, in the beginning of the bed shrinking, little decrease of the hydraulic radius of the packed bed of iron bearing materials occurs, and only small increase in the pressure drop appears. With further bed shrinkage, the decrease in the void space among particles becomes predominant compared to the exclusion of the pore volume inside the particles. This causes the decrease in the hydraulic radius of the packed bed and large pressure drop is generated.

\subsection{Void (Flow Path) Network}

The flow path structure in the packed bed before deformation is shown in Fig. 13. This path structure is obtained by following the procedure explained in the section 2.3. In this figure, the side view of the packed bed (width: 0.6 $\mathrm{m}$ ) is displayed with the transparent packed particles. The dark blue particles in the top part of the packed bed are weight particles. Due to the transparent particles, the flow path structure within 5-10 layers of particles from the front face of the packing vessel can be seen. Around each particle, cage-like flow path is formed as shown in Fig. 4(b). Neighboring cage-like flow paths connected one another, and a huge network structure is formed. In this figure, the flow paths are colored by the path width. As shown in Fig. 3, a flow path stays among three particles. The path width is defined as the average length of three perpendicular lines from the centers of surrounding particles to flow path line. Additionally, the path width is normalized by the particle radius. The flow path network shown in this figure consists of mainly green colored flow paths. Therefore, many flow paths with width range from 1.125 to 1.625 [-] exist. The flow paths colored yellow to red (wider than $1.625[-]$ ) are 


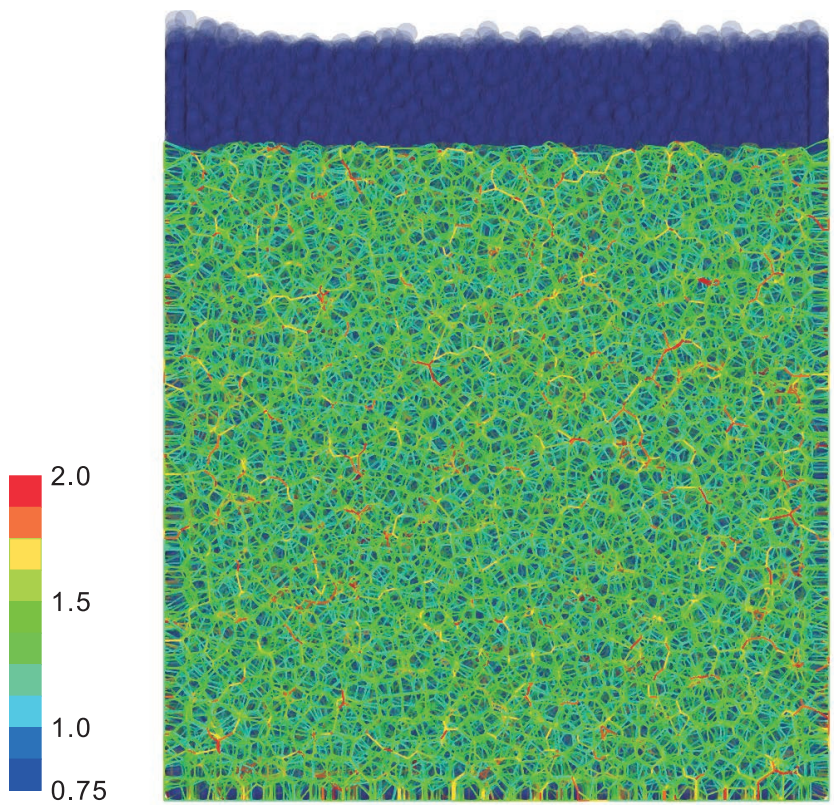

Fig. 13. Flow path distribution in the packed bed before deformation.
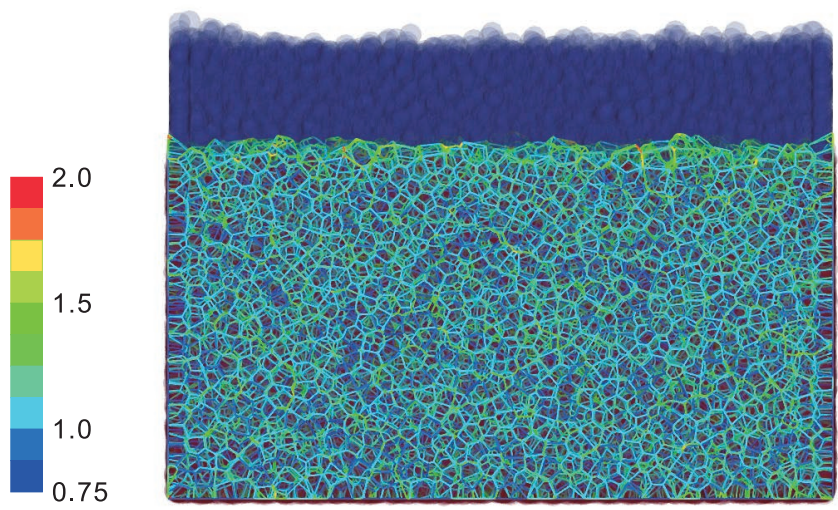

Fig. 14. Flow path network in deformed packed bed $\left(E=1.0 \times 10^{6}\right.$ Pa) without coke mixing.

distributed over the packed bed. The gas can easily flow through these wide paths.

Figure 14 shows the flow path network in the packed bed of $1.0 \times 10^{6} \mathrm{~Pa}$ particles without coke mixing. In this condition, the flow path network mainly consists of green or blue colored paths, and yellow or red paths are hardly observed. Note that the width of blue and dark blue paths is narrower than $1.0[-]$, in other words paths are closed. This means that the average path width becomes narrower compared to the bed before deformation, and some flow paths are choked by the bed deformation.

Figure 15 shows the flow path network in the packed bed of $1.0 \times 10^{6} \mathrm{~Pa}$ particles with $30 \%$ of coke mixing. The flow path network in this condition also mainly consists of green and blue colored flow paths. But more green colored and less blue colored flow paths can be seen compared to the Fig. 14. Additionally, a few yellow or red colored flow paths can be observed in the bed. This suggest that the mixing coke particles to the ore bed widens the average flow path width.

For more quantitative analysis of the flow path structure, probability density of the flow path width and length is cal-

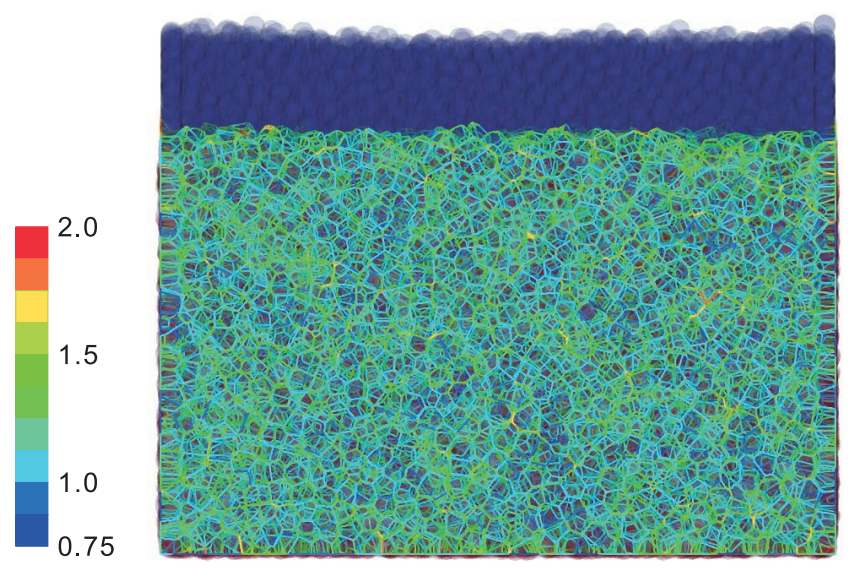

Fig. 15. Flow path network in deformed packed bed $\left(E=1.0 \times 10^{6}\right.$ $\mathrm{Pa}$ ) with $30 \%$ of coke mixing.

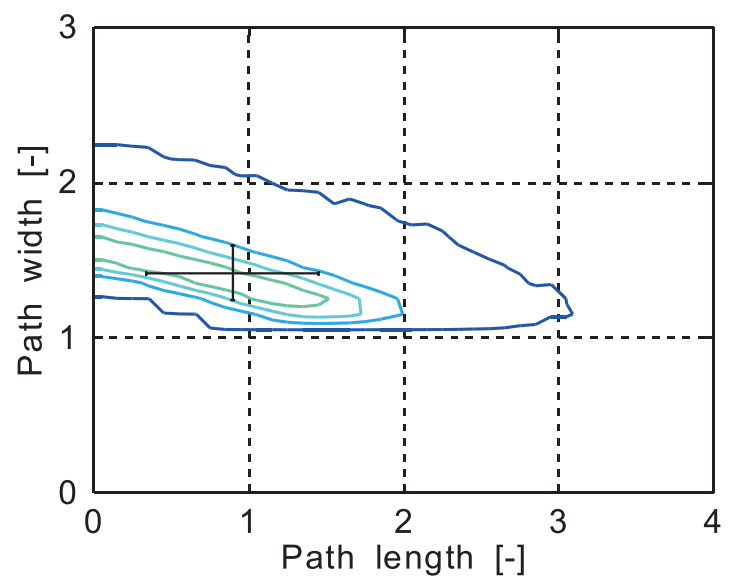

(a) Bed before deformation

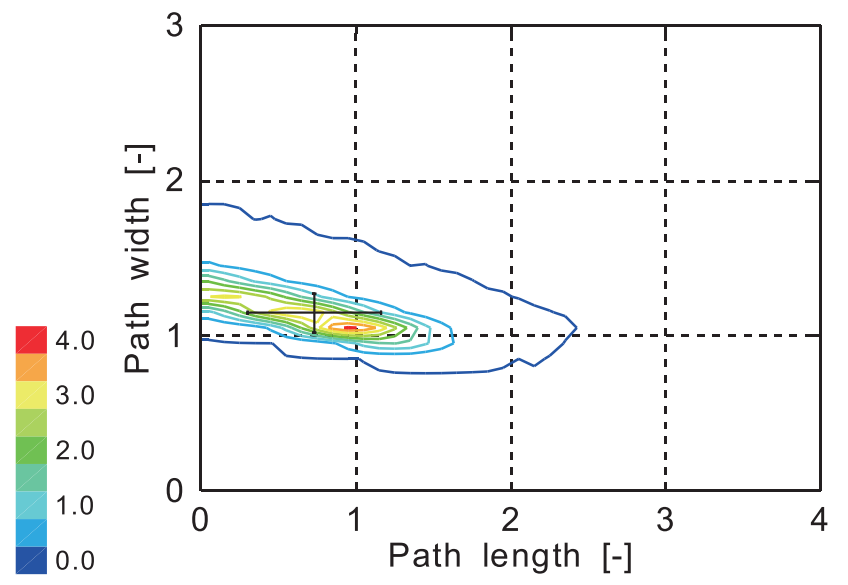

(b) Deformed bed $\left(E=1.0 \times 10^{6}[\mathrm{~Pa}]\right)$

Fig. 16. Distribution of probability density of path width and length of bed without coke.

culated. The probability density is defined as

$$
P(w, l)=\frac{f(w, l)}{\Delta w \cdot \Delta l}
$$

where, $f(w, l)$ is relative frequency having path width $w$ and path length $l[-], \Delta w$ is dividing width of path width, and $\Delta l$ is dividing width of path length. In this analysis, dividing widths of both width and length are set at $0.1[-]$.

Figure 16 shows the distribution of probability density (herein after, PD) of flow path width and length in the bed 
without coke mixing. Figure 16(a) is of the bed before deformation, and (b) is of the bed with $1.0 \times 10^{6} \mathrm{~Pa}$ of the Young's modulus. In this figure, the value of the minimum (blue) contour is 0.0033 [-]. Additionally, the plus mark in the figure specify the average values of path width and length, and their standard deviation. In both cases, the PD shows band-like distribution. In the bed before deformation (Fig. 16(a)), the path width is distributed from 1.1 to 2.3 $[-]$, and the path length is distributed up to $3.1[-]$. Note

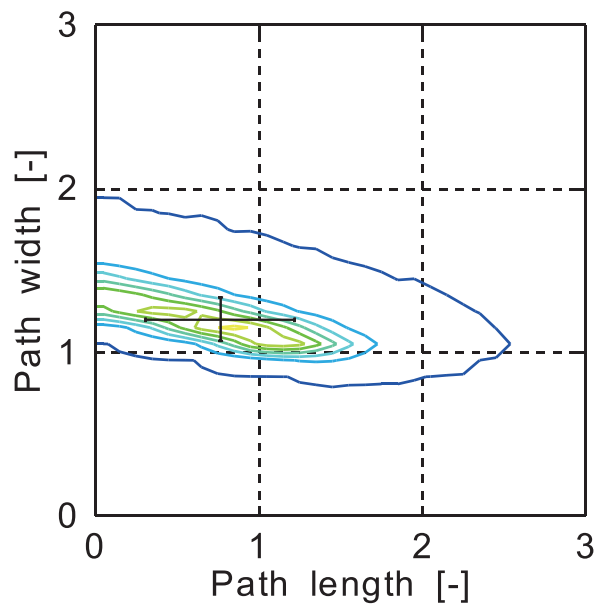

(a) Overall

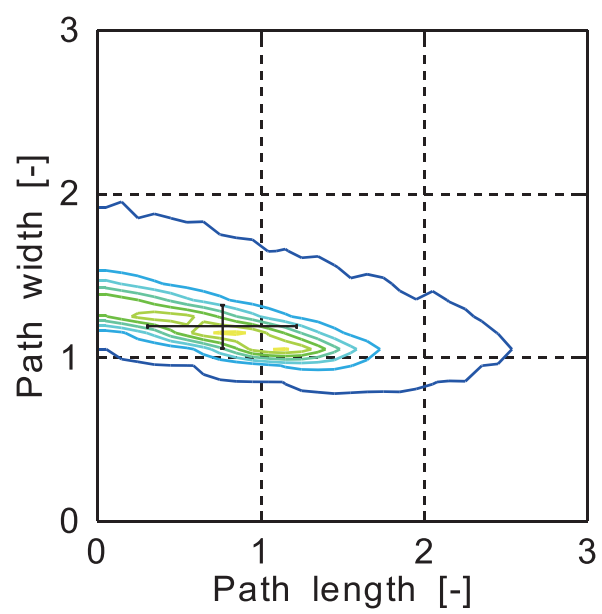

(b) Ore

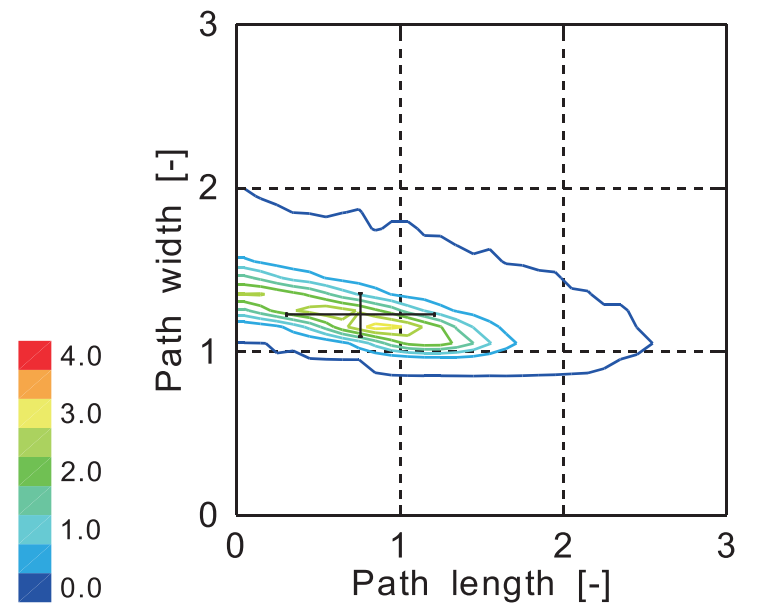

(c) Coke

Fig. 17. Distribution of probability density of path width and length of deformed bed with $30 \%$ of coke mixing. that the flow path width in the closest packing of monodispersed spheres is $1.15 \cong 2 / \sqrt{3}[-]$. The average width and length are 1.42 and $0.89[-]$, respectively. The short length paths mainly located at branching and merging parts of the flow path network. These can be seen as small green rectangle in Fig. 4(b). Such paths locate relatively far from the particle center, and the PD of such short paths shows the maximum around 1.6 [-] of path width. The maximum PD path width decreases with increase in the path length, the width becomes $1.3[-]$ when the length is $1.2[-]$. In the deformed bed (Fig. 16(b)), the PD distribution shifts toward narrower width and shorter length. The average width and length are 1.15 and $0.73[-]$, respectively. The standard deviations of width and length become smaller compared to the bed before deformation. The maximum value of the PD is higher than $4.0[-]$ while one in the before-deformation bed is less than $2.0[-]$. In the deformed bed, the paths of which width are less than $1.0[-]$ exist, contrarily there are no such path in before-deformation bed. It is considered that the paths less than $1.0[-]$ width correspond to choked paths. Therefore, certain number of the flow paths are closed due to the bed deformation.

Figure 17 shows the flow path PD distributions of deformed packed bed with coke mixing. The coke mixing ratio is $30 \%$ and the Young's modulus of the packed particles is $1.0 \times 10^{6} \mathrm{~Pa}$. The average path width and length are 1.20 and $0.76[-]$, and are slightly wider and longer than the case without coke mixing. As mentioned above, the shrinkage of the coke mixing bed is smaller than the bed without coke. With decrease in the shrinkage, the choking of the flow path is restrained. The PD of flow paths around ore (deformed) and coke (non-deformed) particles are separately calculated and shown in Figs. 17(b) and 17(c). The average widths of the paths around ore particles and coke particles are, 1.19 and 1.23 [-], respectively. The path width around the coke particles are maintained at higher value. Comparing Figs. 17(b) and 17(c), the probability of the path of which width is narrower than $1.0[-]$ is smaller around coke particles. This means that the flow paths around the mixed coke (non-deformed) particles tend to be maintained as open flow paths.

These results suggest that the mixing of nut coke particles into ore layer restrains the bed shrinkage when the ore layer softens and deforms. Some parts of the gas flow paths around the coke particles escape from the choking. Finally, it is estimated that the permeability of the softening ore bed with nut coke mixing is maintained higher level compared to the bed with nut coke mixing.

\section{Conclusions}

In this study, the void structure in the deforming packed bed was discussed. The examined packed bed consisted of mono-dispersed spherical particles and was numerically formed by using the discrete element method. From the obtained state of the packed particle, the characteristics of the void space, concretely the hydraulic radius and the flow path structure, were extracted. With increase in the bed deformation, the actual hydraulic radius deviated from the one calculated from the bed shrinkage, and it caused the large difference in the pressure drop in the packed bed. 
The structure of the flow path network was successfully extracted from the particle packing structure. The variation of the width and the length of the flow path with bed deformation was revealed. The variations of the pressure drops in the reduction test under loading and in the softening ore layer with coke mixing can be explained based on the obtained characteristics of the void structure.

\section{REFERENCES}

1) C. E. Loo, L. T. Matthews and D. P. O'Dea: ISIJ Int., 51 (2011), 930.

2) K. Sunahara, T. Natsui, K. Shizawa and Y. Ujisawa: ISIJ Int., 51 (2011), 1322.

3) N. Takeuchi, Y. Iwami, T. Higuchi, K. Nushiro, N. Oyama and M. Sato: ISIJ Int., 54 (2014), 791.

4) X. Liu, S. Wu, W. Huang, K. Zhang and K. Du: ISIJ Int., 54 (2014), 2089

5) A. Kemppainen, K. Ohno, M. Iljana, O. Mattila, T. Paananen, E.-P. Heikkinen, T. Maeda, K. Kunitomo and T. Fabritius: ISIJ Int., 55 (2015), 2039 .

6) M. Iljana, A. Kemppainen, T. Paananen, O. Mattila, E.-P. Heikkinen and T. Fabritius: ISIJ Int., 56 (2016), 1705.

7) X. Liu, T. Honeyands, S. Mitra, G. Evans, B. Godel, R. G. Acres, F. Salvemini, D. O'Dea and B. Ellis: ISIJ Int., 58 (2018), 2150.

8) D. J. Gavel, A. Adema, J. Stel, J. Sietsma, R. Boom and Y. Yang: ISIJ Int., 59 (2019), 778.

9) J. Yagi, K. Takeda and Y. Omori: Trans. Iron Steel Inst. Jpn., 22 (1982), 884.

10) P. R. Austin, H. Nogami and J. Yagi: ISIJ Int., 37 (1997), 458.

11) X. F. Dong, A. Yu. S. J. Chew and P. Zulli: Metall. Mater. Trans. B, 41 (2010), 330

12) Y. Shen, B. Guo, S. Chew, P. Austin and A. B. Yu: Metall. Mater. Trans. B, 46 (2015), 432

13) P. A. Cundall and O. D. L. Strack: Geotechnique, 29 (1979), 47.

14) R. Y. Yang, R. P. Zou, K. J. Dong, X. Z. An and A. Yu: Comput Phys. Commun., 177 (2007), 206.

15) Z. Zhou, H. Zhu, A. Yu and P. Zulli: ISIJ Int., 50 (2010), 515.

16) H. Kurosawa, S. Matsuhashi, S. Natsui, T. Kon, S. Ueda, R. Inoue and T. Ariyama: ISIJ Int., 52 (2012), 1010.

17) S. Matsuhashi, H. Kurosawa, S. Natsui, T. Kon, S. Ueda, R. Inoue and T. Ariyama: ISIJ Int., 52 (2012), 1990.

18) T. Kon, S. Natsui, S. Matsuhashi, S. Ueda, R. Inoue and T. Ariyama: Steel Res. Int., 84 (2013), 1146.

19) S. Ueda, T. Kon, H. Kurosawa, S. Natsui, T. Ariyama and H.
Nogami: ISIJ Int., 55 (2015), 1232.

20) S. Ergun: Chem. Eng. Prog., 48 (1952), 89.

21) T. Sugiyama, H. Sato, M. Nakamura and Y. Hara: Tetsu-to-Hagané, 66 (1980), 1908 (in Japanese).

22) X. Zhou, Y. Duan, X. Huai and X. Li: Particuology, 11 (2013), 715.

23) L. W. Rong, Z. Y. Zhou and A. B. Yu: Powder Technol., 285 (2015), 146.

24) A. Singhal, S. Cloete, S. Radl, R. Q. Ferreira and S. Amini: MAYFEB J. Chem. Eng., 1 (2016), 10.

25) R. Mohanty, S. Mohanty and B. K. Mishra: J. Taiwan Inst. Chem. Eng., 63 (2016), 71.

26) S. Das, N. G. Deen and J. A. M. Kuipers: Chem. Eng. Sci., 160 (2017), 1 .

27) Z. Wu, Y. Wu, S. Tang, D. Liu, S. Qiu, G. H. Su and W. Tian: Prog. Nucl. Energy, 109 (2018), 29.

28) N. Jurtz, M. Kraume and G. D. Wehinger: Rev. Chem. Eng., 35 (2019), 139.

29) S. Natsui, S. Ishihara, T. Kon, K. Ohno and H. Nogami: Chem. Eng. J., 392 (2020), 123643.

30) H. Nogami: ISIJ Int., 60 (2020), 1495.

31) S. Watakabe, K. Takeda, H. Nishimura, S. Goto, N. Nishimura, T. Uchida and M. Kiguchi: ISIJ Int., 46 (2006), 513.

32) Y. Kashihara, Y. Iwai, T. Sato, N. Ishiwata and M. Sato: ISIJ Int., 55 (2015), 1237.

33) Y. Kashihara, Y. Iwai, N. Ishiwata, N. Oyama, H. Matsuno, H. Horikoshi, K. Yamamoto and M. Kuwabara: ISIJ Int., 57 (2017), 665.

34) W. Zhao, M. Chu, H. Wang, Z. Liu, J. Tang and Z. Ying: ISIJ Int., 58 (2018), 1989.

35) D. J. Gavel, A. Adema, J. Stel, J. Sietsma, R. Boom and Y. Yang: ISIJ Int., 60 (2020), 451.

36) D. J. Gavel, A. Adema, J. Stel, C. Kwakernaak, J. Sietsma, R. Boom and Y. Yang: ISIJ Int., 59 (2019), 778.

37) J. Ishii, R. Murai, I. Sumi, Y. Yang and R. Boom: ISIJ Int., 57 (2017), 1531.

38) F. Larachi, R. Hannaoui, P. Horgue, F. Augier, Y. Haroun, S. Youssef, E. Rosenberg, M. Prat and M. Quintard: Chem. Eng. J., 240 (2014), 290.

39) R. Hannaoui, P. Horgue, F. Larachi, Y. Haroun, F. Augier, M. Quintard and M. Prat: Chem. Eng. J., 262 (2015), 334.

40) P. I. Chigada: Chem. Eng. Res. Des., 89 (2011), 230.

41) N. Reboul, E. Vincens and B. Cambou: Granul. Matter, 10 (2008), 457.

42) J. Wang, J. Yang, B. Sundén and Q. Wang: Appl. Therm. Eng., 172 (2020), 115141

43) S. Natsui, A. Sawada, H. Nogami., T. Kikuchi and R. O. Suzuki: ISIJ Int., 60 (2020), 1453.

44) Y. Tsuji, T. Tanaka and T. Ishida: Powder Technol., 71 (1992), 239. 